\title{
DESIGN OF PROGRESSIVE PRESS TOOL FOR AN ALPHA METER COMPONENT
}

\author{
Vinay Kumar A V $\mathbf{1}^{1}$, D Ramegowda ${ }^{2}$ \\ ${ }^{\text {I}}$ Student, M. Tech, Government Tool Room and Training Centre, Mysuru, India \\ ${ }^{2}$ Principal, Department of PG Studies, Government Tool Room and Training Centre, Mysuru, India
}

\begin{abstract}
The sheet metal manufacturing Design and development of different components is one of the important phases. like shearing, piercing and blanking etc. There is a highly complex process and leads to various uncertainties.

Progressive tool components are modeled in solid works with selected dimensions from the given $2 D$ diagram and design calculations.. Results obtained from theoretical calculations are in good agreement with empirical dimensions of CAD model.
\end{abstract}

Keywords: Die, punch, piercing, CAD.

\section{INTRODUCTION}

The design and manufacture of press tools, or punches and dies, is a branch of production technology that has extended into many lines of engineering manufacture over the past seventy years. There is no doubt that the accuracy achieved by new ideas in design and construction applied by the press tool designer, coupled with increased speed and rigidity of the presses etc, used have all contributed toward maintaining this form of metal tooling well to the force as a means of obtaining pleasing, yet strong, durable articles that can withstand severe day-today usage.

More and more it has become the practice to produce from sheet metal by some form of pressing process, work pieces that would have been made from bar, forging or casting two or three decades ago. Also, the handling of both strip material and semi-finished components has assumed an importance simply because fast and efficient movement means cheap products from operators who do not suffer fatigue from the handling of awkward or heavy components. However, it should not be forgotten that press design has made many advances in recent years in common with, for example, the machine tool industry, and machines are now available that are capable of withstanding the heavy stresses set up in many modern production process.

\section{TYPES OF PRESS TOOLS}

Progressive Tools

$>$ Combination Tools

$>$ Compound Tools

$>$ Bending tools

A Progressive Tools-Progressive tool performs many operations at different stages in each stroke. The stock strip is advanced through a series of stations that form one or more distinct press working operations on the strip to get the component.
B Combination Tools- A die in which cutting operation and non-cutting operations on a part is accomplished in single stroke of the press. The cutting operations may be blanking, piercing, trimming and are combined with non cutting operations which may include bending, forming, drawing and embossing etc.

C Compound Tools- Similar to a progressive tools, a compound tool also produce blanks having pierced holes but the difference being that the former performance the operations at more than one station where as the later performs both the operations simultaneously at the same station. The conventional positions of the blanking punch and die are inverted. The blanking punch being clamped to the die shoe forms part of the bottom tool, whereas, the blanking die being clamped to the die head forms part of the top tool. The piercing punches assume the conventional position and inside the blanking die opening piercing punches are mounted with a punch holder. Their mating piercing dies are formed in the blanking punch.

\section{ELEMENTS OF PROGRESSIVE TOOLS}

A-Die Set- It is one of the basic elements of the stamping industry which can be defined as a sub press unit consisting of a bottom plate and top plate together with guide pillars and bushes by means of which the top and bottom plates are aligned. The purpose of die set is to utilize the entire die assembly.

B-Top Plate- The upper working member of the tool is called the top plate. The punch assembly including the punch holder and thrust plate is mounted on the top plate. The tool shank, which locates the whole tool centrally with the press ram, is also screwed into the top plate. 
C-Punch Back Plate- While performing the cutting operation, the punch exerts an upward thrust. So a hardened plate to prevent it from digging into the soft-top plate should back up punch. It is made out of case hardened tool steels.

D- Punch Plate- The punch is usually fixed to a plate with a light press fit. Punch holder holds all types of cutting and non-cutting punches to ensure alignment between punch and die it is made out of ST-42.

E- Punches- A punch is the male member of a press tool to get a component from the strip. It is made out of good quality alloy steel.

F- Stripper Plate- When cutting action is over, the punch withdraws from the die but the stock strip also will move along with punch. So for next operation strip cannot be moved forward. To facilitate this function one plate is fixed above the die plate. This removes the strip from the punch is called stripper. It guides punches and pilots in this plate to ensure alignment with punch and die.

G- Die Plate- A die block is defined as the block or plate from which the die profile is cut. It is usually lower member of the tool. It provides cutting edge. The die opening has different designs and the design is selected after looking in the requirements and facilities available.

H- Bottom Plate- Bottom plate gives cushioning effect to the die as well as provides enough space for the tool to be clamped to the press bed. There may be opening in the base plate, which allows the blank, or slug to fall and clear off from the tool. The die assembly including stripper, all bottom elements are mounted on the bottom plate.

I- Guide Pillar and Guide Bush-These are very important function in press-tool. Pillar and bushes guide the moving and fixed half of the tool in the press and also it is used to ensure accurate alignment between the punches an.

\section{SHEARING THEORY AND ACTION}

Shearing is the method of cutting a sheet metal (shear out) without forming chips. The material is stressed from punch and dies side simultaneously in sections that lies parallel to the forces applied by means of shear blades or punches and die. The cutting action that occurs on blanking or piercing is that similar to that of chip formation by a cutting tool. The punch contracts the work material supported by the die and a pressure build up occurs. The shearing or cutting forces necessary to bring about shearing or rapture of the material depend primarily upon the shearing strength of the material, thickness and cutting length.

Three critical stages of shearing are
$\square$ Deformation
$\checkmark$ Penetration
Fracture

The metal is subjected to both tensile and Compressive stresses, stretching beyond the elastic limit. Then the Deformation, Penetration and Fracture will takes place.

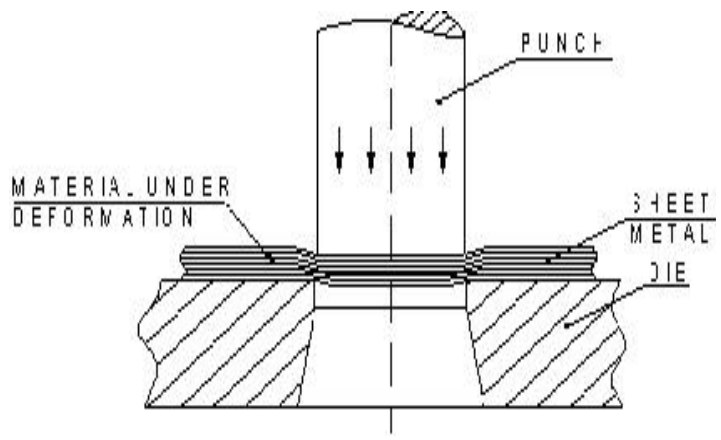

Fig 1 Deformation Stage

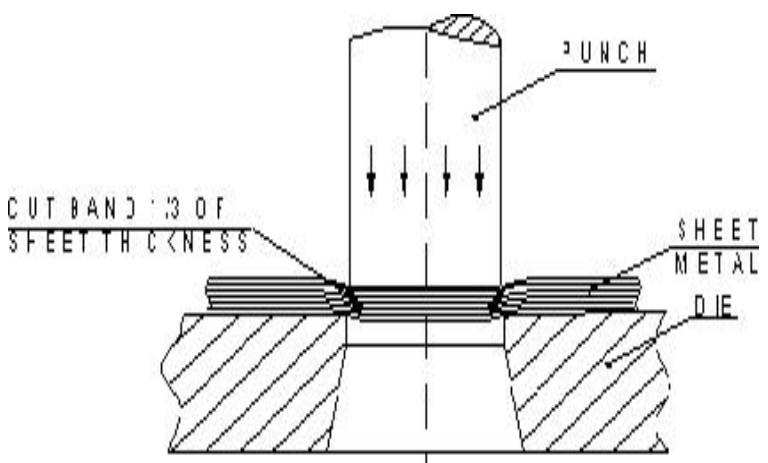

Fig 2 Penetration Stage

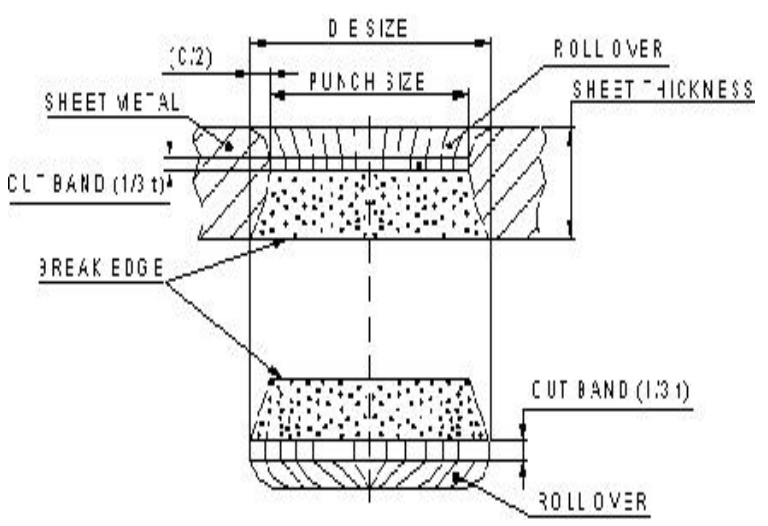

Fig 3 Fracture Stage

\section{COMPONENT STUDY}

Material: aluminum

Thickness: $0.5 \mathrm{~mm}$

Shear Force: $82.7 \mathrm{M}$ pa

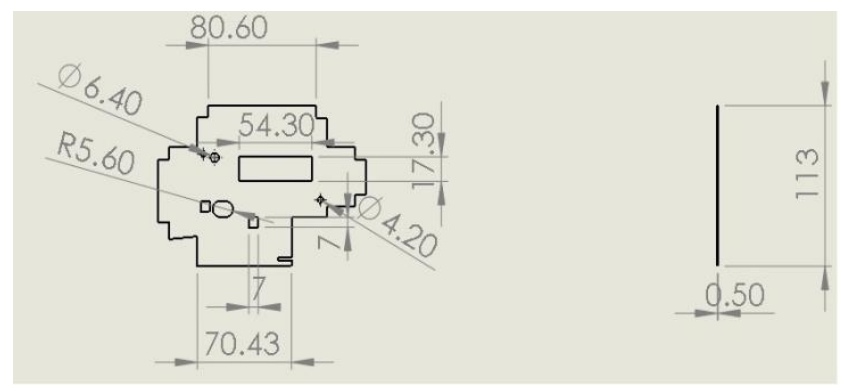

Fig 4 Component Diagram 


\section{TOOL DESIGN}

Tool design is one of the most skill full job, because almost all the components which are produced using press tool will be demanded high dimensional accuracy therefore at most care should be taken will designing the press tool.

\subsection{Press Tool Design Considerations}

Several points have to be taken into considerations during press tool design process.

- All the parts are designed should have the capability to bear the forces.

- Sufficient space should be provided to load the stock.

- $\quad$ Die set should be made of proper material.

\subsection{Selection of Material}

Along with the important design consideration one should also know about the proper material selection for components of a die set various types of tool steels with their suitability for components of die set. Material or selected tool steel should be Very hard to resist wear and strong to bear load and at the same time die set components may have very complicated shape, design and need very accurate sizing. So here we use D2 material for both Die and Punch because D2 steel is an air hardening, high-carbon, high chromium tool steel. It has high wear and abrasion resistant properties.

Table 1 Mechanical Properties of D2 Material

\begin{tabular}{|l|l|l|}
\hline Properties & values & units \\
\hline Elastic modulus & 210000 & $\mathrm{~N} / \mathrm{mm}^{2}$ \\
\hline Poisons ratio & 0.3 & \\
\hline Shear modulus & 7900 & $\mathrm{~N} / \mathrm{mm}^{2}$ \\
\hline Mass density & 7700 & $\mathrm{Kg} / \mathrm{m}^{3}$ \\
\hline Tensile strength & 1736 & $\mathrm{~N} / \mathrm{mm}^{2}$ \\
\hline Compressive strength & 2150 & $\mathrm{~N} / \mathrm{mm}^{2}$ \\
\hline Yield strength & 1532 & $\mathrm{~N} / \mathrm{mm}^{2}$ \\
\hline Thermal conductivity & 20 & $\mathrm{~W} /(\mathrm{m}-\mathrm{K})$ \\
\hline Specific heat & 460 & $\mathrm{~J} /(\mathrm{kg}-\mathrm{K})$ \\
\hline
\end{tabular}

\subsection{Calculation}

\subsubsection{Strip Layout}

Clearance per side of sheet $-3 \mathrm{~mm}$

$\%$ area of utilization $=$ area of blank x no of rows Pitch $\mathrm{x}$ width

Area Of Blank- 122663.26mm

No Of Rows- 1

Pitch-158.52mm

Width-119mm

$$
\begin{aligned}
& =\frac{12663.26 \times 1}{158.52 \times 119} \\
& =67.12 \%
\end{aligned}
$$

\subsubsection{Shear Force (Blanking)}

Shear force $=\mathrm{L} \times \mathrm{S} \times \mathrm{T}_{\max }$

$\mathrm{L}$ - length of cut $\quad \mathrm{L}=557.37 \mathrm{~mm}$

$\mathrm{S}$ - Thickness of sheet $\mathrm{S}=0.5 \mathrm{~mm}$

$\mathrm{T}_{\text {max }}$ - shear strength $\mathrm{T}_{\max }=82.7 \mathrm{~N} / \mathrm{mm}^{2}$

$$
\begin{aligned}
& =557.37 \times 0.5 \times 82.7 \\
& =23047.15 \mathrm{~N} / \mathrm{mm}^{2}
\end{aligned}
$$

\subsubsection{Shear Force (Piercing)}

$\mathrm{F}_{\mathrm{s} 1}=20.05 \times 0.5 \times 82.7=829.068 \mathrm{~N} / \mathrm{mm}^{2}$

$\mathrm{F}_{\mathrm{s} 2}=12.99 \times 0.5 \times 82.7=537.22 \mathrm{~N} / \mathrm{mm}^{2}$

$F_{\mathrm{s} 3}=13.29 \times 0.5 \times 82.7=549.54 \mathrm{~N} / \mathrm{mm}^{2}$

$F_{s 4}=143.05 \times 0.5 \times 82.7=5915.33 \mathrm{~N} / \mathrm{mm}^{2}$

$\mathrm{F}_{\mathrm{s} 5}=39.25 \times 0.5 \times 82.7 \quad=1622.95 \mathrm{~N} / \mathrm{mm}^{2}$

$\mathrm{F}_{\mathrm{s} 6}=28.06 \times 0.5 \times 82.7=1160.37 \mathrm{~N} / \mathrm{mm}^{2}$

$\mathrm{F}_{\mathrm{s} 7}=25.92 \times 0.5 \times 82.7=1071.88 \mathrm{~N} / \mathrm{mm}^{2}$

Total Fs $($ piercing $)=11686.36 \mathrm{~N} / \mathrm{mm}^{2}$

Total Shear Force $=23047.15+11686.36$

$$
=34733.51 \mathrm{~N} / \mathrm{mm}^{2}
$$

\subsubsection{Stripping Force}

Stripping force $=20 \%$ of total shear force $=6946.7 \mathrm{~N} / \mathrm{mm}^{2}$

\subsubsection{Press Tonnage}

Total Press Capacity=

Total Shear Force +Stripping Force

$$
=41680.212 \mathrm{~N} / \mathrm{mm}^{2}
$$

Press Tonnage $=\underline{\text { press capacity }}=\underline{41680.212}$

$$
70 \% \quad 0.7
$$

$$
=59543.16 \mathrm{~N} / \mathrm{mm}^{2}
$$$$
=59.54 \text { tons }
$$

$$
\underline{59.54}=6.075 \text { tons }
$$

9.8

Hence 50 tonnage machine is used for this tool

\subsubsection{Clearance}

Clearance $=\mathrm{c} \times \mathrm{x}^{3} \sqrt{\mathrm{T}}_{\max }$

$=0.01 \times 0.5 \times 3 \sqrt{82.7}$

$=0.05 \mathrm{~mm}$ 


\subsubsection{Design Of Die Block}

Thickness of die $\left(\mathrm{T}_{\mathrm{d}}\right)={ }^{3} \sqrt{\mathrm{fs}}$

$$
\begin{aligned}
& =\sqrt[3]{ } 41680.212 \\
& =34.67=35 \mathrm{~mm}
\end{aligned}
$$

Thickness of bottom plate $=1.5 \mathrm{~T}_{\mathrm{d}}=52.5 \mathrm{~mm}$

Thickness of top plate $=1.25 \mathrm{~T}_{\mathrm{d}}=43.75 \mathrm{~mm}$

Thickness of stripper Plate $=0.75 \mathrm{~T}_{\mathrm{d}}=26.25 \mathrm{~mm}$

Thickness of punch holder $=0.5 \mathrm{~T}_{\mathrm{d}}=17.5 \mathrm{~mm}$

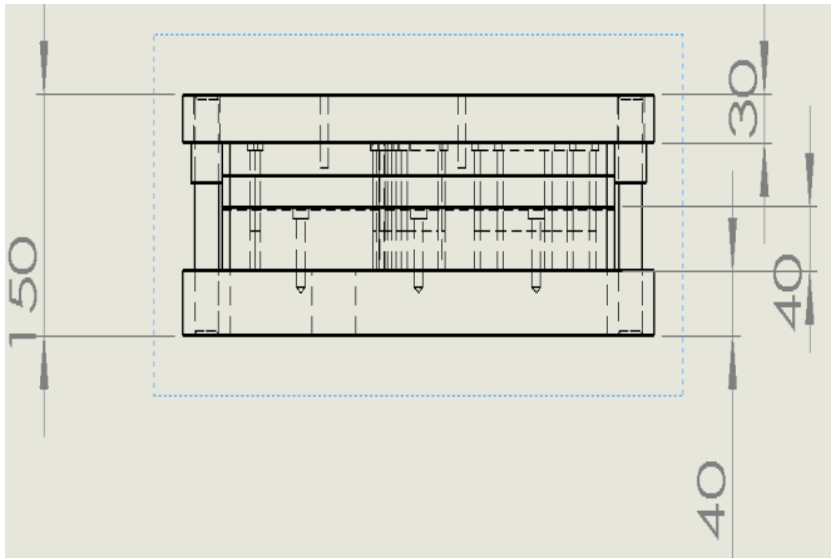

Fig 5 Front view of the assembly

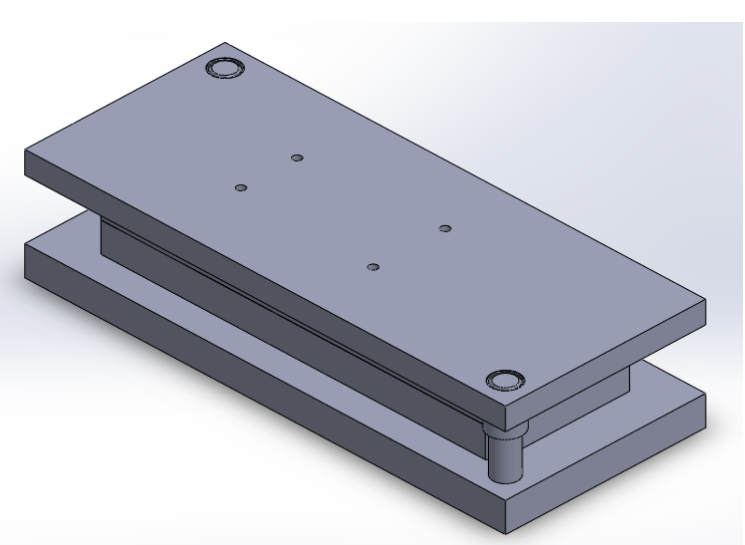

Fig 6 3D model of the tool assemly

\section{PUNCH AND DIE ANALYSIS}

After designing and modeling, the press tool is analyzed. Punch and Die analysis is carried under computer aided engineering software to ensure that the design is safe. Punch and Die are the parts which undergo repeated loads in press tools, which is expensive too. Computer aided engineering software it provides an opportunity to improve the design of the part prior to manufacturing. Hence based on the analysis Result necessary material or geometrical changes are incorporated.

\subsection{Die Analysis of Blanking Tool}

Initially modeling is done then boundary conditions and suitable material is applied to the die. The below figure shows the stress distribution of die under the applied loading condition. The orange and blue color in the plot indicates the maximum and minimum stress distribution respectively.

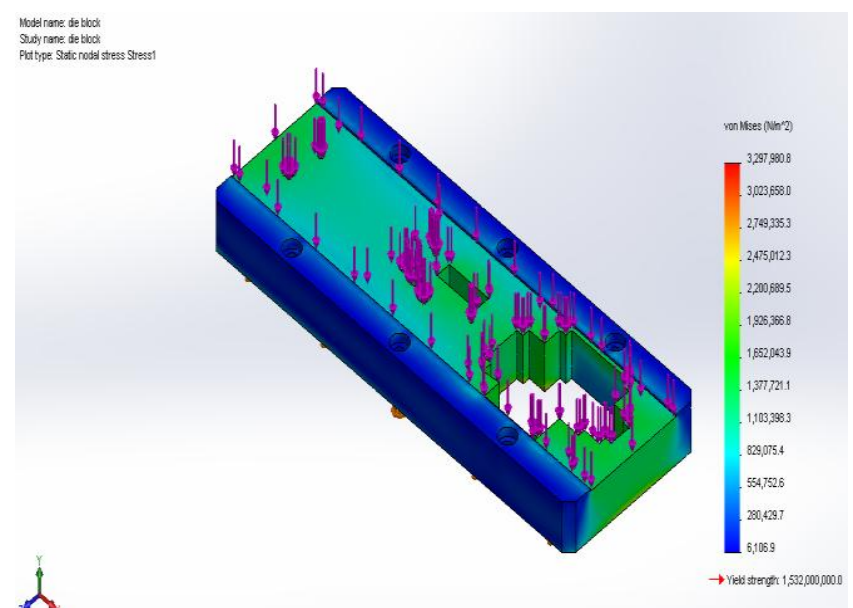

Fig 7 Static Stress Analysis of Blanking Die

\subsection{Punch Analysis}

Initially modeling is done then boundary conditions and suitable material is applied to the die. The below figure shows the stress distribution of die under the applied loading condition. The orange and blue color in the plot indicates the maximum and minimum stress distribution respectively.

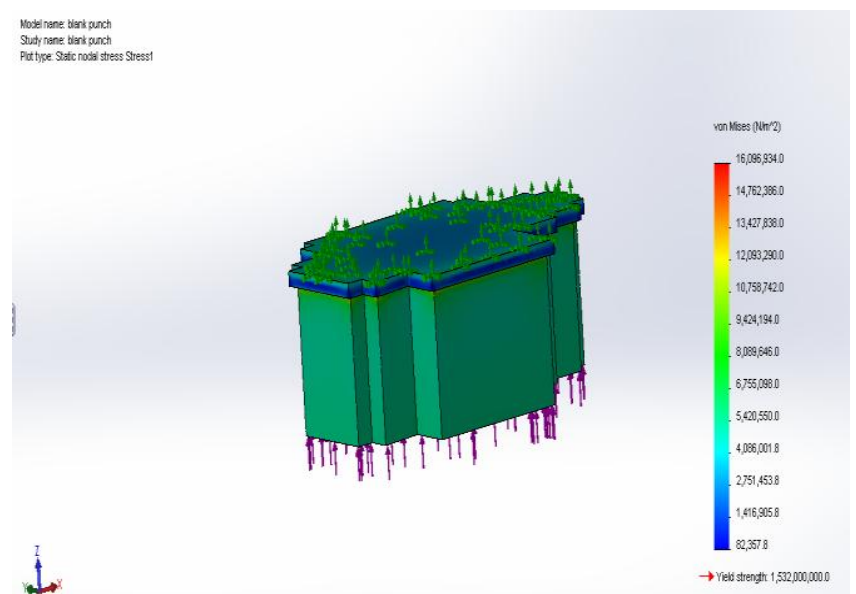

Fig 8 .Static Stress Analysis of blanking punch

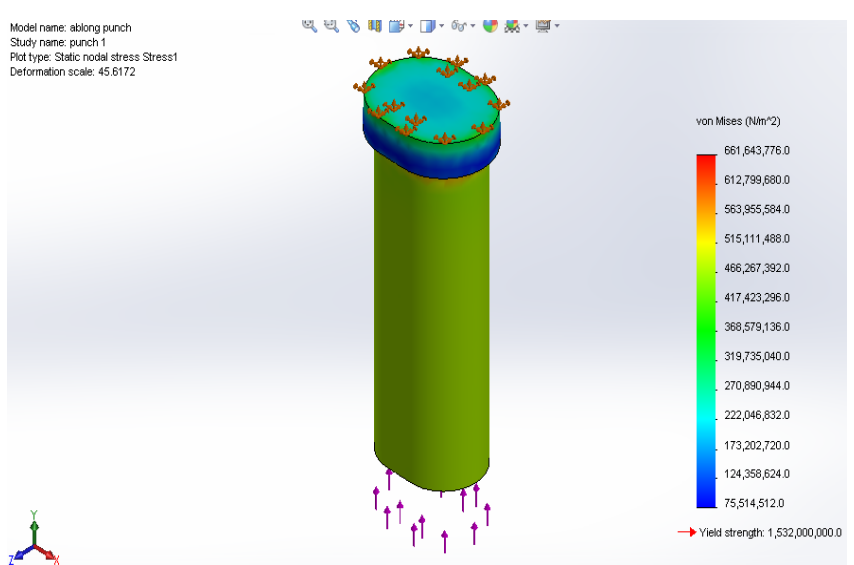

Fig 9 Static Stress Analysis of piercing punch 


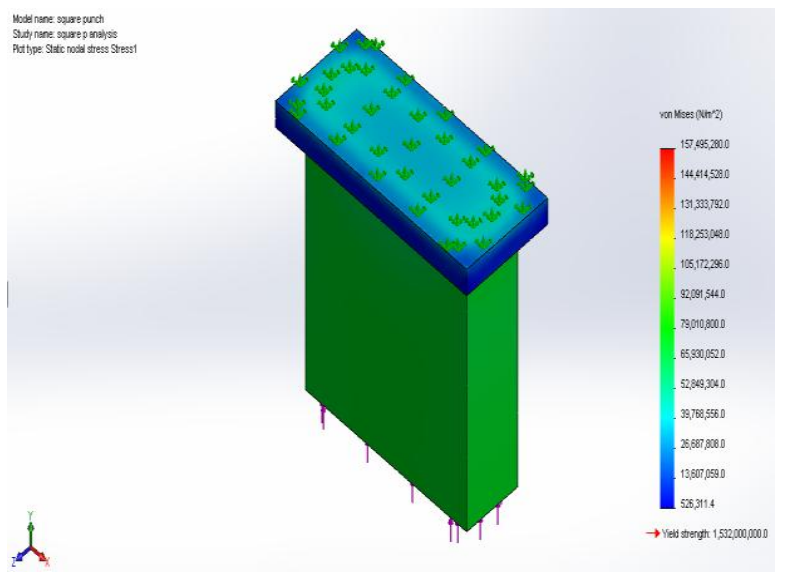

Fig 10 Static Stress Analysis of rectangle hole punch

\subsection{Analysis Result Table}

Table 2 Maximum Stress distribution in punch and die of blanking tool

\begin{tabular}{|l|l|l|l|}
\hline $\begin{array}{l}\text { Sl } \\
\text { no }\end{array}$ & Type & Value & Unit \\
\hline 1 & die & 16.1 & $\mathrm{~N} / \mathrm{mm}^{2}$ \\
\hline 2 & Rectangle punch & 157.5 & $\mathrm{~N} / \mathrm{mm}^{2}$ \\
\hline 4 & Oblong punch & 661.6 & $\mathrm{~N} / \mathrm{mm}^{2}$ \\
\hline
\end{tabular}

\section{CONCLUSION}

In this work some significant aspects of press tool design for alpha meter component is discussed and also detail study and analysis were carried out. Punch and Die analysis of the tool were carried out and the design was found to be safe. Both in punch and die maximum stress developed was very less when compared to the yield stress value. Through analysis it confirms that the material selected for both punch and die is safe. Punch and die designed is made detachable so that only the damaged part is replaced. By incorporating finite element method overall production rate is optimized.

\section{ACKNOWLEDGEMENTS}

I am Vinay Kumar A V, Doing M.Tech (Tool Engineering) in Government Tool Room and Training Centre, Mysore. Currently carrying out my final semester project work on Press Tool.

\section{REFERENCES}

[1] Seon-Bong Lee, Dong-Hwan Kim, Byung-Min Kim. 'Development of optimal layout design system in multihole blanking process.' Journal of Materials Processing Technology 130-13120 December 2002

[2] Design and Analysis of Progressive Tool Ch.Mastanamma 1, K.Prasada Rao 2,Dr. M.Venkateswara Rao3 International Journal of Engineering Research \& Technology (IJERT) Vol. 1 Issue 6, August - 2012

[3] N B Suresh, A Learners Guide To Press Tool, published by pannaga international acedamy, Fourth Edition[2010]
[4] Prakash H. Joshi, Press Tool: Design And Construction, Wheelers Publications.

[5] GT\&TC Data Hand Book

[6] Md Inaithul Rehaman \#1, P Satish Reddy \#2, Matta Manoj \#3, N.Guru Murthy \#4 Design and Analysis of Progressive Die for Chain Link Plate International Journal of Science Engineering and Advance Technology, IJSEAT, Vol 2, Issue 11 ISSN 2321-6905 November-2011. 